УДК: 633.15.631.527

\title{
ИЗУЧЕНИЕ КОМБИНАЦИОННОЙ СПОСОБНОСТИ НОВЫХ РАННЕСПЕЛЫХ ДИГАПЛОИДНЫХ ЛИНИЙ КУКУРУЗЫ
}

\author{
Перевязка Дмитрий Сергеевич \\ Перевязка Наталья Игоревна \\ младшие научные сотрудники \\ Научный руководитель: Супрунов Анатолий Иванович \\ д-р с.-х. наук \\ Национальный центр зерна им. П.П. Лукьяненко
}

Аннотация: Потребность в гибридах кукурузы, возделываемых на территории Российской Федерации, растёт с каждым годом. Поэтому на первое место выходит селекционная работа и, непосредственно, работа селекционера по созданию новых гибридов кукурузы различных групп спелости. Однако успешная работа в данном направлении напрямую зависит от качества и методов оценки используемого исходного материала для создания новых гибридов. В данной работе проведена оценка общей и специфической комбинационной способности дигаплоидных линий, использующихся для создания новых раннеспелых гибридов кукурузы.

Ключевые слова: гибриды, комбинационная способность, дигаплоидные линии, исходный материал.

\section{STUDY OF THE COMBINATION ABILITY OF NEW EARLY DIGAPLOID CORN LINES}

Perevyazka Dmitriy Sergeevich
Perevyazka Natalia Igorevna
Suprunov Anatoly Ivanovich

\begin{abstract}
: the demand for corn hybrids cultivated on the territory of the Russian Federation is growing every year. Therefore, selection work and, directly, the work of the breeder on the creation of new hybrids of maize of various ripeness groups comes out on top. However, successful work in this direction directly depends on the quality and methods of evaluating the source material used to create new
\end{abstract}


hybrids. This work evaluates the general and specific combining ability of dihaploid lines used to create new early maturing maize hybrids.

Key words: hybrids, combining ability, dihaploid lines, starting material.

Введение. Селекционная работа начинается с подбора и оценки исходного материала, служащего отправной точкой при создании новых гибридов и сортов культурных растений. От исходного материала и его генетических и качественных характеристик зависит то, каким получится новый гибрид или сорт, и основная работа селекционера сводится к изучению и оценке исходного материала, выбраковке несоответствующих генотипов и отбору только тех генотипов, которые соответствуют высоким требованиям, предъявляемым селекционером.

В настоящее время существует большое количество различных методов оценки нового исходного материала, но основным является - изучение его комбинационной способности. Преимуществом данного метода является изучение непосредственного взаимодействия различных генотипов между собой и возможности дальнейшего отбора только хорошо комбинирующих между собой генотипов исходного материала [1,2].

Материал и методы. В качестве исходного материала нами были выбраны 6 линий из генетической коллекции НЦЗ: КР 802 МВ, КР 768/914-1-2, КР 733/6 МВ, КР 244 МВ, КР 801 МВ, КР 3070 МВ. С целью создания нового исходного материала на начальном этапе было создано 5 гибридных комбинаций с участием лучших исходных линий кукурузы с широкой генетической основой: КР $244 \mathrm{MB}$ х КР 802 МВ, КР 733/6 МВ х КР 802 МВ, КР 244 МВ х КР 76891/4-1-1, КР 3070 МВ х КР 802 МВ, КР 801 МВ х КР 733/6 МВ. На получившихся гибридных комбинациях была заложена работа по получению дигаплоидных линий кукурузы. По результатам работы по хозяйственно - ценным признакам было отобрано 33 раннеспелые линии кукурузы, к которым, впоследствии, было подобрано три тестера: КР 742 М, КР 714 М и КР 742 М х 770. По результатам работы была проведена работа по изучению общей и специфической комбинационной способности новых дигаплоидных линий и тестеров кукурузы.

Результаты. Одним из ключевых факторов, оказывающих влияние на величину комбинационной способности, являются климатические условия, сложившиеся в месте проведения исследований. Работа по данному направлению проводилась в условиях Центральной зоны Краснодарского края 
на опытных полях НЦЗ им. П.П. Лукьяненко. Погодные условия, сложившиеся в центральной зоне Краснодарского края представлены на рисунке 1.

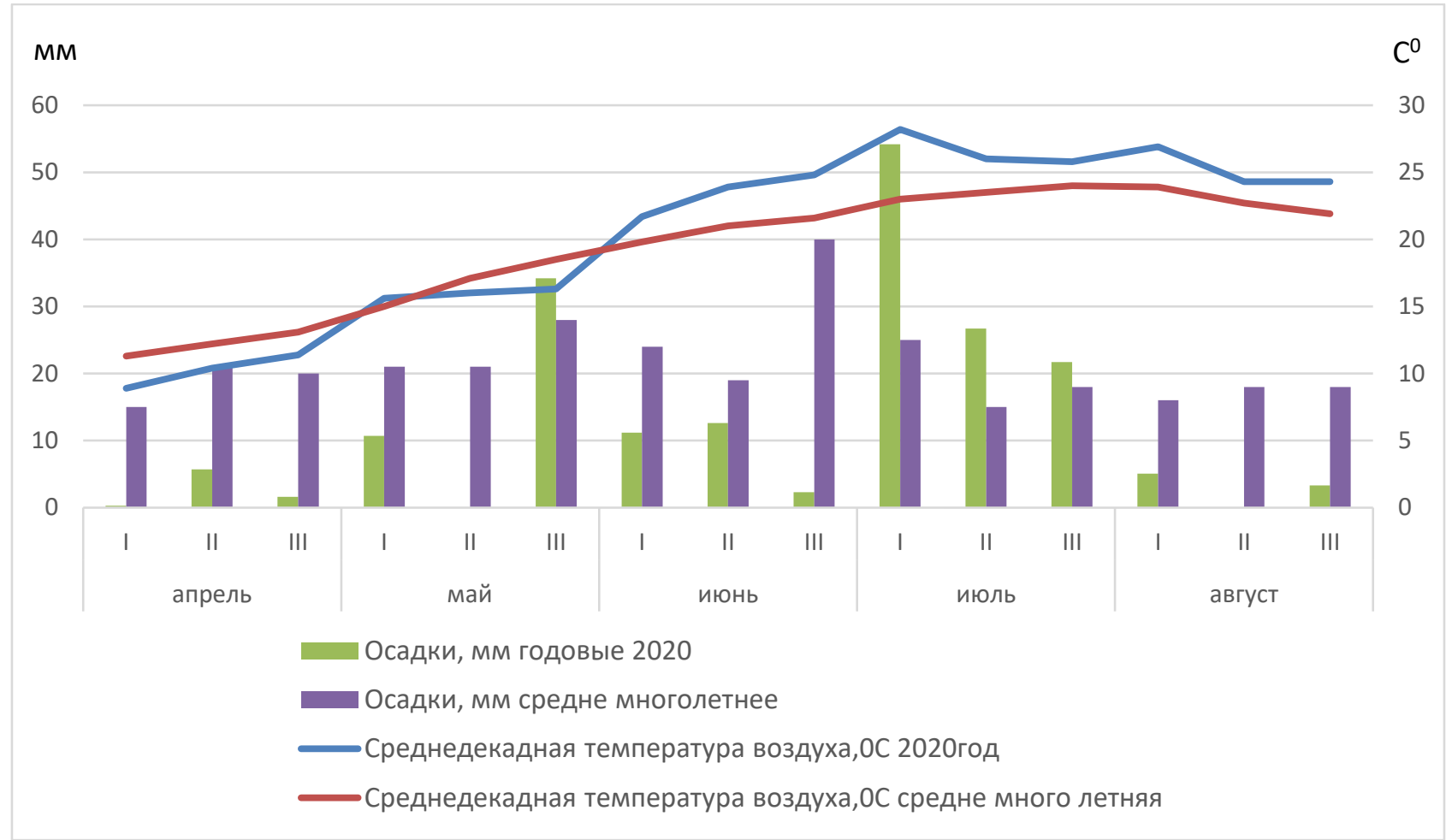

Рис. 1. Погодные условия 2020 года (по данным метеостанции НЦ3)

Исходя из данных, полученных на рисунке 1 можно сделать следующие выводы: низкое количество осадков и высокие дневные температуры в важные периоды вегетации раннеспелой группы растений кукурузы (2 декада июня 2 декада июля) можно назвать весьма негативными для роста и развития гибридов кукурузы. Несмотря на количество осадков выше среднемноголетнего показателя в 1 - 3 декадах июля, высокие дневные температуры не позволили сформировать гибридам кукурузы высокие показатели урожайности, напрямую влияющие на величину комбинационной способности.

Следующий этап работы заключался непосредственно в изучении величин комбинационной способности. Первым этапом изучалась величина общей комбинационной способности - способности исследуемой линии, хорошо комбинировать с используемыми тестерами. Результаты работы представлены в таблице 1 . 
Таблица 1

Эффекты ОКС раннеспелых линий и тестеров кукурузы,

Краснодар, 2020 год

\begin{tabular}{|c|c|}
\hline \multirow{2}{*}{ Наименование линий } & Эффекты ОКС раннеспелых линий, год \\
\cline { 2 - 2 } & 2020 год \\
\hline $1524 / 2-1$ & 2,23 \\
\hline $1524 / 7$ & 1,29 \\
\hline $1524 / 8$ & 3,72 \\
\hline $1525 / 32$ & 9,43 \\
\hline $1525 / 80$ & 5,71 \\
\hline $1525 / 86$ & 16,02 \\
\hline $1525 / 89$ & 9,08 \\
\hline $1526 / 1$ & 17,60 \\
\hline $1527 / 1$ & 1,80 \\
\hline $1528 / 24$ & 9,98 \\
\hline $1529 / 9$ & 2,09 \\
\hline $244 \mathrm{MB}$ & 17,30 \\
\hline $802 \mathrm{MB}$ & 12,39 \\
\hline $76891 / 4-1-1$ & 11,82 \\
\hline HCР 05 & 3,50 \\
\hline
\end{tabular}

По результатам, представленным в таблице 1, можно сделать следующие выводы: в данной таблице представлены новые дигаплоидные раннеспелые линии кукурузы, эффекты ОКС которых были положительными в 2020 году проведения исследований. Представленные результаты свидетельствуют нам о том, что данные линии хорошо комбинируют с используемыми тестерами. Однако, изучение только общей комбинационной способности не даёт полного представления об изучаемой линии, поэтому далее нами была выполнена работа по изучению специфической комбинационной способности новых раннеспелых дигаплоидных линий кукурузы. Результаты работы представлены в таблице 2. 
Таблица 2

Константы и вариансы СКС раннеспелых линий кукурузы, Краснодар, 2020 год

\begin{tabular}{|c|c|c|c|c|}
\hline \multirow{2}{*}{$\begin{array}{c}\text { Наименование } \\
\text { линий }\end{array}$} & \multicolumn{3}{|c|}{$\begin{array}{c}\text { Константы CКС (Sij) раннеспелых линий, } \\
\text { тестера }\end{array}$} & \multirow{2}{*}{$\begin{array}{c}\text { Вариансы } \\
\text { СКС } \\
(\sigma 2 \mathrm{Si})\end{array}$} \\
\hline & $742 \mathrm{M}$ & $714 \mathrm{M}$ & $742 \mathrm{M} \times 770$ & \\
\hline $1524 / 2-1$ & $-8,04$ & $-1,61$ & 9,66 & 77,93 \\
\hline $1524 / 13$ & $-10,47$ & 1,73 & 8,74 & 92,16 \\
\hline $1525 / 7$ & 9,48 & $-3,03$ & $-6,45$ & 67,97 \\
\hline $1525 / 10$ & $-5,87$ & 12,38 & $-6,51$ & 112,71 \\
\hline $1525 / 20$ & 13,90 & $-5,31$ & $-8,59$ & 145,33 \\
\hline $1525 / 32$ & 8,43 & $-8,79$ & 0,36 & 71,84 \\
\hline $1525 / 79$ & 10,84 & $-7,47$ & $-3,37$ & 90,05 \\
\hline $1525 / 80$ & 12,94 & $-12,83$ & $-0,11$ & 163,72 \\
\hline $1525 / 81$ & $-7,50$ & 11,23 & $-3,73$ & 95,75 \\
\hline $1527 / 1$ & $-3,25$ & $-6,57$ & 9,82 & 72,78 \\
\hline $1528 / 24$ & $-4,47$ & 8,47 & $-3,99$ & 51,47 \\
\hline $1529 / 14$ & $-12,07$ & 12,52 & $-0,45$ & 148,94 \\
\hline $802 \mathrm{MB}$ & $-5,43$ & 10,61 & $-5,18$ & 82,15 \\
\hline 76891/4-1-1 & $-8,58$ & $-0,04$ & 8,61 & 71,50 \\
\hline HCP 05 & & & & \\
\hline
\end{tabular}

Исходя из данных, полученных в таблице 2, можно сделать следующие выводы: линии, представленные в таблице 2 отличаются наибольшими показателями варианс СКС, что свидетельствует нам о том, что в комбинациях данных линий с изучаемыми тестерами наблюдаются наибольшие изменения по показателю урожайности зерна, и что именно в данных комбинациях необходимо искать зависимости взаимодействия различных генотипов между собой для создания высокопродуктивных гибридов кукурузы.

Заключение. Таким образом, нами была проведена работа по изучению комбинационной способности нового линейного материала. Результаты данной работы позволят нам изучить взаимодействия различных генотипов исходного материала между собой в определённых климатических условиях, и сформулировать дальнейшие пути его использования в селекционных программах для создания высокопродуктивных гибридов кукурузы. 


\section{Список литературы}

1. Гульняшкин А.В. Оценка комбинационной способности самоопылённых линий в топкросных скрещиваниях / А.В. Гульняшкин, И.М. Чилашвили, С.С. Попов // Проблемы и тенденции инновационного развития агропромышленного комплекса и аграрного образования России. 2012. - № 2. - C. 131 - 133.

2. Супрунов А.И. Оценка нового исходного материала для селекции средних и среднепоздних гибридов кукурузы / А.И. Супрунов, И.М. Чилашвили, С.С. Попов // Проблемы и тенденции инновационного развития агропромышленного комплекса и аграрного образования России. 2012. - № 2. - C. 167 - 171.

( Н.И. Перевязка, Д.С. Перевязка, А.И. Супрунов, 2021 